\title{
In Process Quality Control Factors Affecting Potency of Fowl Cholera Vaccine
}

\author{
Muhammad Danish Mehmood ${ }^{1}$, Mahmood Hussian Qazi ${ }^{1}$, Khushi Muhammad ${ }^{3}$, Faisal Amin ${ }^{4}$, Huma Anwar ${ }^{2}$ \& \\ Muhammad Ismail ${ }^{2}$ \\ ${ }^{1}$ Institute of Molecular Biology and Biotechnology, University of Lahore, Pakistan \\ ${ }^{2}$ Ottoman Pharma (Immuno Division), Raiwind Road Lahore, Pakistan \\ ${ }^{3}$ University of Veterinary and Animal Sciences, Lahore, Pakistan \\ ${ }^{4}$ Grand Parent Diagnostic Laboratory, Lahore, Pakistan \\ Correspondence: Muhammad Danish Mehmood, Department of Microbiology, Director Technical's at Ottoman \\ Pharma Immuno Division, Lahore, Pakistan. E-mail: drdanishmehmood@gmail.com
}

Received: December 18, 2018

Accepted: January 19, 2019

Online Published: February 10, 2019

doi:10.5539/ijb.v11n2p23

URL: https://doi.org/10.5539/ijb.v11n2p23

\begin{abstract}
Fowl cholera (FC) is one of the respiratory syndromes of commercial layer, breeder and broiler farms in Pakistan. The disease is mainly controlled by vaccination. In the present study, effect of "in process quality control" factors such as amount of immunogen, chemical nature of adjuvant, fractions of bacterial culture and its storage on potency of the vaccine was investigated. Immunogen amount $\left(10^{11} \mathrm{CFU} / \mathrm{ml}\right)$ induced serum anti-Pasteurella multocida ELISA (anti-PM-ELISA) antibody titer in the vaccinated birds on 32 days post vaccination that was significantly higher $(\mathrm{P}<0.05)$ than that of $10^{9}$ and $10^{10} \mathrm{CFU} / \mathrm{ml}$. Montanide based whole culture vaccine induced better antibody response as compare to aluminum hydroxide gel. Washed culture of P. multocida (bacterial sediment) induced significantly higher anti-PM-ELISA antibody titer as compared to the vaccine prepared from purified LPS or whole culture vaccine $(p<0.05)$. Storage of oil based $F C$ vaccine at refrigerated temperature for six months did not affect its immunogenicity.

It is concluded that amount of immunogen, chemical nature of adjuvant, freeing of bacterial culture from LPS and media components and maintenance of cold chain are in process quality control factors affecting potency of the vaccine.
\end{abstract}

Keywords: Fowl Cholera, Pasteurella Multocida, Montanide, ELISA

\section{Introduction}

Fowl Cholera (FC) is one of the contagious bacterial diseases of domestic and wild avian species. It is characterized by facial edema, blackening of comb and wattles, off feed and water, gasping, dull depressed with high morbidity (up to 50\%) and mortality up to $10 \%$ (Choudhury et al., 1992; Glisson et al., 2003). Disease severity is enhanced in hot humid environment, overcrowding, age, $\mathrm{pH}$ and sucrose level of clay (Bredy \& Botzler, 1989; Hutyra et al., 1949; Petrides \& Bryant, 1951; Samuel et al., 1999a; Titche, 1979).

It is caused by Pasteurella multocida (P. multocida). The organism is serotyped on the basis of capsular (A) and somatic antigens. These serotypes are A:1, A:3, A:5 and A:9 serotype and rarely cause a problem in mammalian species (Benkirane \& De Alwis, 2002; Mohamed et al., 2012; Rhoades \& Rimler, 1989). Serotype A:1 of $P$. multocida is the common cause of the disease in Asian countries (Farooq et al., 2007; Shivachandra et al., 2006). Being acute nature of the bacterial disease, treatment with antibiotics is not successful unless carried out at an early stage. In poultry industry the disease is mainly controlled through mass vaccination program. The commonly used vaccine against FC is oil or gel based inactivated whole culture bacterial vaccine or live attenuated bacterial vaccine (Boyce et al., 2000). Killed vaccines have certain limitations. Alum precipitated vaccine although used extensively but, induces immunity for short period of time 4-6 months, whereas oil based vaccine provides protection up to one year but oil based vaccines in poultry induces facial edema, abscess formation and post vaccination shocks (Littledike, 1993). These problems might be due to bacterial capsule (lipopolysaccharide-LPS) that is produced extensively during bacterial growth in bio-fermentor (latest advanced technique of bacterial biomass production). The immunity against $P$. multocida is due to LPS as well as its outer 
membrane protein (OMP). The present study is therefore, planned to investigate in process quality control factors such as amount of immunogen per dose, chemical nature of adjuvant, fractions of the bacterial culture and shelf life of the vaccine.

\section{Materials and Methods}

\subsection{Cultivation of P. Multocida}

Fresh culture of P. multocida (serotype A) was obtained from Ottoman Pharma 10-Km Raiwind road, Lahore for preparation of different types of vaccine. P. multocida was grown in biofermentor containing BHI broth at $37^{\circ} \mathrm{C}$ for 24 hours with constant stirring (Shah et al., 2008). The broth culture was inactivated with $0.5 \%(\mathrm{v} / \mathrm{v})$ formalin (Merck). Sterility of the chemically inactivated culture was determined by its inoculation on BHI blood agar plates and subsequently their incubation at $37^{\circ} \mathrm{C}$ for 24 hours and safety was determined by its inoculation $(1 \mathrm{ml})$ through deep intramuscular route in two susceptible birds.

\subsection{Preparation of Vaccines}

Vaccines containing different amount of immunogens $\left(10^{11}, 10^{10}, 10^{9} \mathrm{CFU} /\right.$ dose $)$, chemical nature of adjuvants (Montanide ISA70MVG, aluminium hydroxide gel, no adjuvant) and fractions of the culture (bacterial washed culture, whole culture and supernatant) were prepared (Sarwar et al., 2015).

\subsection{Experimental Design}

Eighty broilers (Six day old) were selected and randomly divided into eight groups each having ten birds. Each bird of group 1, 2 and 3 was vaccinated with montanide ISA 70MVG based FC vaccine containing $10^{9}, 10^{10}$ and $10^{11} \mathrm{CFU} / \mathrm{ml}$, respectively. Each bird of group 4 and 5 was vaccinated with FC vaccine containing, aluminium hydroxide gel and without adjuvant, respectively. Each bird of group 6 and 7 was primed with oil based vaccine containing supernatant and sediment culture, respectively. The birds of group 8 served as unvaccinated control.

\subsection{Monitoring of Seroconversion of Vaccinated Birds}

Blood sample $(2 \mathrm{ml})$ was collected from wing vein of each of birds of group one to eight on zero, 16, 32 and 48 days post priming in disposable syringes. Each of the blood samples were kept undisturbed at refrigeration temperature and subsequently at $37^{\circ} \mathrm{C}$ for 2 hours. The serum from each of the sample thus oozed out was transferred to properly labeled vials and stored at $-20^{\circ} \mathrm{C}$ for monitoring of its anti FC ELISA antibody titer using (IDEXX PM) kit (Avakian et al., 1985).

\subsection{Statistical Analysis}

Mean anti-PA-ELISA antibody titer of each group of the vaccine was analyzed statistically using one way variance of analysis (ANOVA) and subsequently Duncan multiple range test (Day \& Quinn, 1989).

\section{Results and Discussion}

Fowl cholera is common problem of commercial poultry farms particularly in countries having hot humid environment and is controlled by vaccination (Benkirane \& Alwis, 2002; Hutyra et al., 1949). Causative agent of the disease (Pasteurella multocida) contains capsular LPS and somatic antigen/OMP. The vaccine is prepared using its capsulated form with the idea to develop antibodies specific to its capsular antigen (Chung et al., 2001; Tsuji \& Matsumoto, 1988b). Moreover, efficacy of the vaccine depends upon density of its culture per dose of vaccine. The density of bacterial culture is controlled by enrichment media BHI both or CYS broth, incubation temperature and time and aeration of the culture during growth period (Shah et al., 2008). The bacterial count $/ \mathrm{ml}$ of the culture was directly proportional to its biomass. Moreover, $\mathrm{FC}$ vaccine containing $7 \mathrm{mg} / 10^{9} \mathrm{CFU} / \mathrm{ml}$ of the dose induced 438 units of anti PM-ELISA antibody titer. Antibody response of the broilers was directly proportional to the amount of immunogen per dose of the vaccine (Figure-I). Higher the amount of immunogen per dose of the vaccine, higher will be the antibody response of the vaccinated host (Ali et al., 2000).

The vaccine without adjuvant showed poor antibody titer in the vaccinated birds that directly related with the retention time of vaccine at the injection site. Poor response of the birds is incriminated to rapid absorption of the immunogen from inoculation site. In case of live attenuated vaccine against the disease, the bacteria retained in the body on account of their multiplication in non-essential sites such as larynx/pharynx of the host. Adjuvants are chemicals that make the immunogen of the vaccine insoluble, hence, enhance its retention time at the inoculation site. These are therefore, used in the veterinary and medical inactivated vaccines. Commonly used adjuvants are mineral oils, aluminium salts (alum and gel), sodium alginate, saponin, lanolin and vegetable oils (Jankovic et al., 1997; Wu et al., 1994; Audibert \& Lise 1993). Mineral oils encapsulate the bacterial antigen and make it water insoluble. Hence, protects rapid absorption of the vaccine from inoculation sites (Wu et al., 1994). Moreover, oil causes irritation at the inoculation site that result in development of local granuloma. As there are 
no lymph nodes in birds and development of such granuloma at vaccine injection site play cardial role in production of immunity (Igyártó et al., 2006). Aluminium hydroxide gel is not irritant so is commonly used in veterinary and medical vaccines. The gel adsorbs the vaccinal antigen, mitigates its direct removal from the inoculation site and hence removed from inoculation site through antigen processing cells. The vaccine material may be processed by local antigen processing and presenting cells (APC) such as macrophages, dendritic cells or $\mathrm{B}$ cells and the protein antigens are presented on its surface in association with class MHC-II antigen/immune associated antigen (Ia Ag) (Jankovic et al., 1997). Avian T helper $\left(T_{h}\right)$ cells can only recognize the foreign specific antigen associated with Ia antigen on surface of the APC and undergo the process of blast formation, proliferation, differentiation into effector and memory cells. The effector cells those survive up to seven days secrete cytokines such as IL-2, IL-4, IL-5, INF- $\gamma$ etc. Production of the cytokines is antigen specific and their action is antigen nonspecific so, these cytokines now specifically activates macrophages, Natural killer (NK) cells, Cytotoxic $\mathrm{T}$ cells $\left(\mathrm{T}_{\mathrm{c}}\right), \mathrm{B}$ cells etc. In this way cytokines potentiate the specific and nonspecific immune responses of the vaccinated birds (Tizzard, 1998). Similarly, avian bursal dependent lymphocytes (B cells) recognize specific free antigen from the inoculation site and undergo the process of blast formation, proliferation and differentiation into plasma cells without development of memory cells. These plasma cells survive for short time and secrete out immunoglobulins (IgM). Such antibody response is always primary response. Such birds can never mount boosting response as a result of boosting. The IgM is effectively detected by IHA test but not by ELISA test. This could be possible reason that indirect ELISA showed undetectable level of antibody response of the birds vaccinated with supernatant of $P$. multocida culture. However, cytokines production may modulate the $\mathrm{T}$ cell independent antigen (carbohydrates/lipids/nucleic acids) processing pathway and results in development of memory cells as well as switching over of IgM synthesis followed by IgG and IgA. The montanide based FC vaccine induced mean anti-PM-ELISA antibody response in the vaccinated broilers that gradually mounted and reached the peak level (570) on 48 days post priming while, the gel based FC vaccine induced anti-PM-ELISA antibody titer that reached at peak level (375) on 48 days post priming (Figure-II). The antibody response of the birds in both the cases started declining thereafter. In this experiment, oil based vaccine induced significantly higher antibody response as compared to gel based vaccines $(\mathrm{p}<0.05)$. Gel based vaccines induce antibody response of short duration and less effective (Audibert et al., 1993; Muneer et al., 2005).

Washed culture of $P$. multocida (bacterial suspension free from LPS and medium component) induced significantly higher antibody titer as compared to the vaccine prepared from purified LPS or whole culture vaccine ( $<<0.05$ : Figure-III). Outer membrane proteins (OMPs) of P. multocida have been studied as potential immunogens, which make them potential vaccine candidates (Lugtenberg et al., 1986; Rhoades \& Rimler, 1989; Lu et al., 1983; Adler et al., 1996). Purified OMP of P. multocida or whole culture induces antibody response in rabbit and show resistance to challenge infection (Adler et al., 1996). The immunity against whole culture is more effective than that LPS alone. Several antigenic components have been investigated as an immunogen against P. multocida infection including purified lipopolysaccharide (LPS) (Rhoades \& Rimler, 1991) and LPS-protein complex (Tsuji \& Matsumoto, 1988b). It was observed that vaccine is stable at refrigerated temperature for six months (Figure-V). The vaccines are stored or transported at refrigerated temperature and are protected from sunlight to minimize the decay of the macromolecules. All chemically inactivated microbial cultures are admixed with preservatives such as thiomersal sodium @ $0.05 \%$ in the culture suspension before addition of adjuvants (Kulcsar et al., 2008).

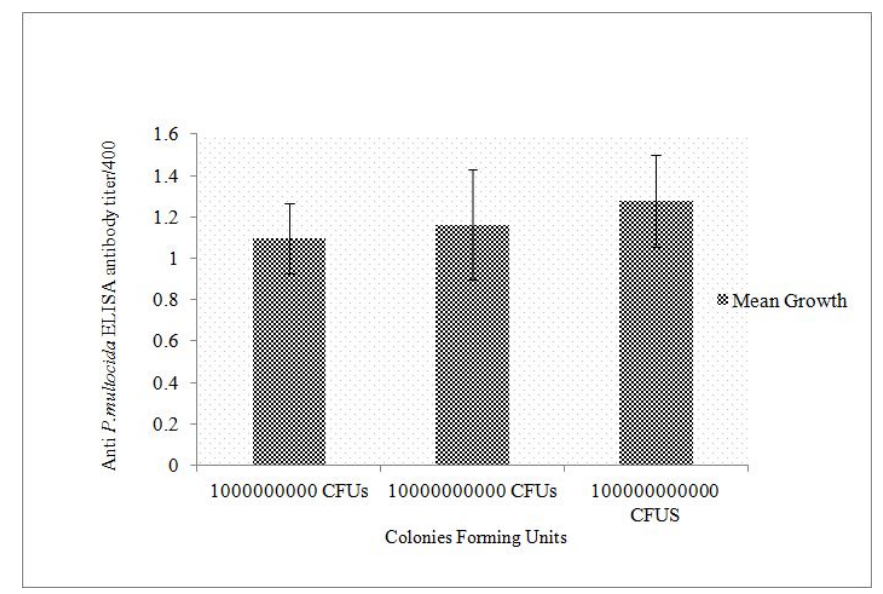

Figure 1. Effect of immunogen (bacterial count/dose of P. multocida vaccine) on antibody response of broiler 


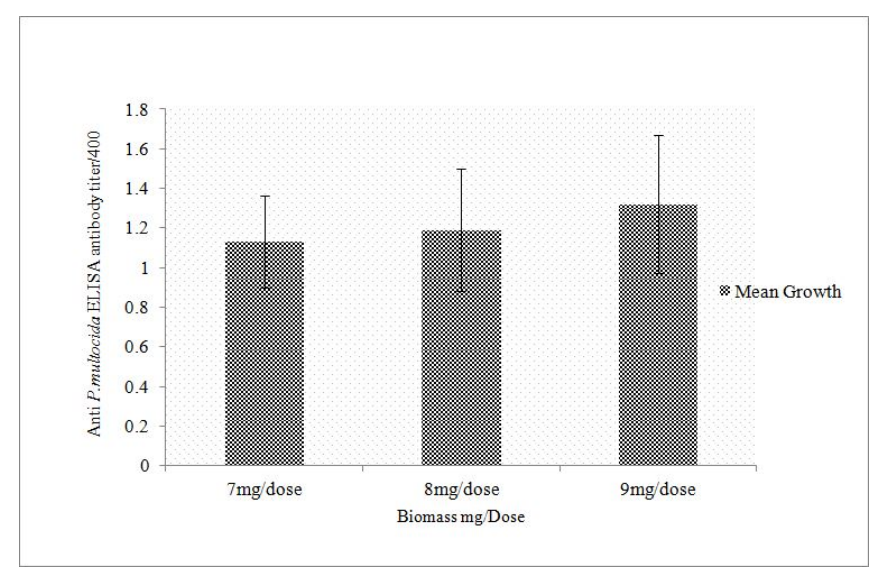

Figure 2. Effect of dry mass of immunogen on antibody response of broilers to oil based Pasteurella multocida vaccine

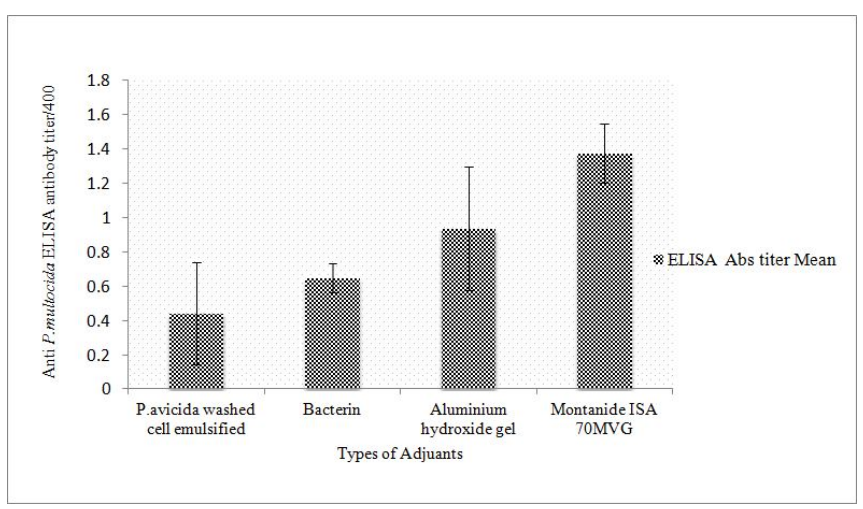

Figure 3. Effect of Adjuvant on Antibody response of Broilers to Pasteurella multocida vaccine

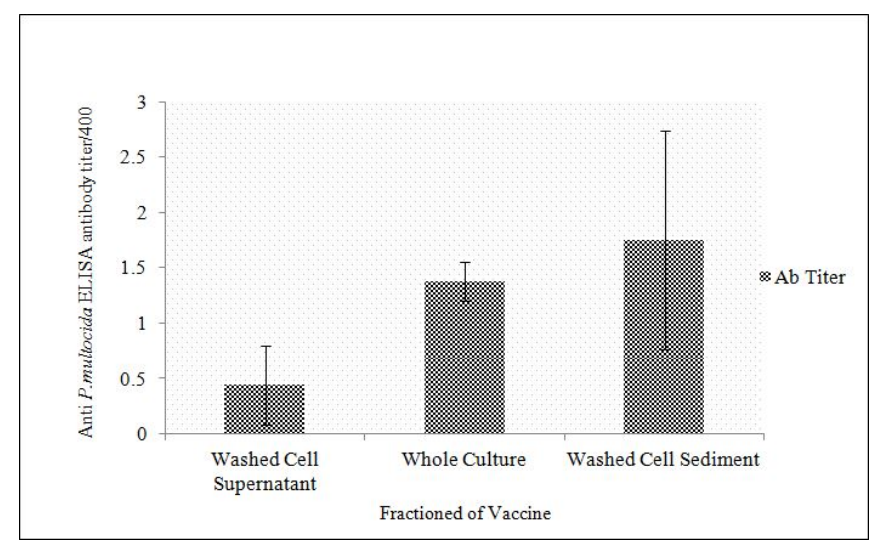

Figure 4. Antibody response of broiler to oil based vaccine containing sediment of $P$. multocida 


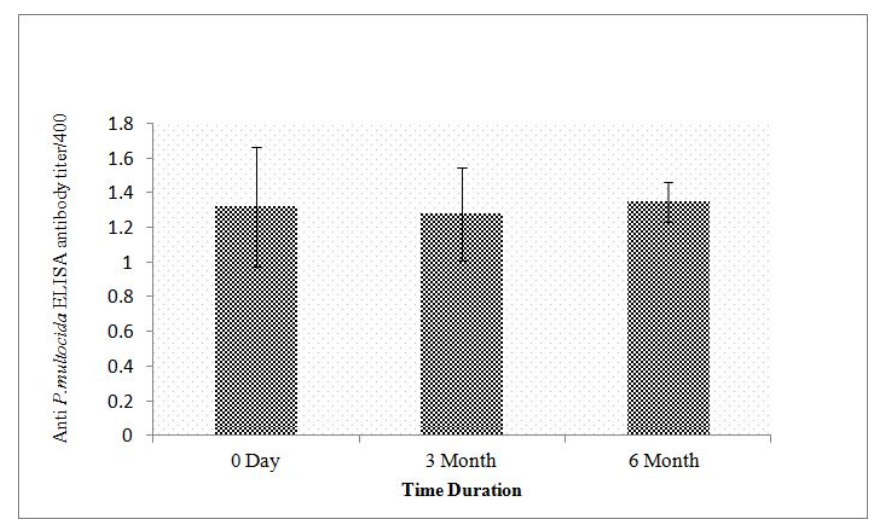

Figure 5. Effect of storage of vaccine on antibody response

It is concluded that amount of immunogen, chemical nature of adjuvant, freeing of bacterial culture from LPS and media components and maintenance of cold chain are in process quality control factors affecting potency of the vaccine.

\section{Conflict of interests}

The authors declare that there is no conflict of interests regarding the publication of this paper.

\section{References}

Adler, B., Chancellor, R., Homchampa, P., Hunt, M., ..., \& Wapling, D. (1996). Immunity and vaccine development in Pasteurella multocida infections. J. Biotechnology, 44(1/3), 139-144.

Ali, Z., Muhammad, K., Hussain, I., \& Hameed, E. (2000). Antibody response of buffaloes to haemorrhagic septicemia vaccine. Intern. J. Agriculture \& Biology, 3, 183-186.

Audibert, F. M., \& Lise, L. D. (1993). Adjuvants: Current status, clinical perspectives and future prospects. Immunol Today, 14, 281-4.

Avakian, A. P., \& Dick, J. W. (1985). Comparison of filter-paper-eluted whole blood with serum in fowl cholera serology using the enzyme-linked immunosorbent assay. Avian Diseases, 29, 1277-1280.

Benkirane, A., \& De-Alwis, M. C. L. (2002). Haemorrhagic septicemia, its significance, prevention and control in Asia. Vet. Med-Czech, 47(8), 234-240.

Boyce, J. D., Chung, J. Y., \& Adler, B. (2000). New Approaches in Vaccine and Bacterial Vaccine Development Pasteurella multocida capsule: Composition, function and genetics. J. Biotechnology, 83(1-2), 153-160.

Bredy, L., \& Botzler, K. G. (1989). The effects of six environmental variables on the survival of Pasteurella Multoeida in water. Journal of Wildlife Diseases, 25, 232-239.

Chaudhuri, S., Mukherjee, S. K., Chatterjee, A., \& Gauguli, J. L. (1992). Isolation of Pasteurella multocida F:3,4 from a stillborn snow leopard. Vet. Rec., 130, 36.

Chung, J. Y., Wilkie, I., Boyce, J. D., Townsen, K. M., ..., \& Adler, B. (2001). Role of capsule in the pathogenesis of fowl cholera caused by Pasteurella multocida serogroup A. Infection and Immunity, 69, 2487-2492.

Day, R. W., \& Quinn, G. P. (1989). Comparisons of treatments after an analysis of variance in ecology. Ecological Monographs, 59, 433-463.

De-Alwis, M. C. L. (1999). Haemorrhagic Septicaemia. ACIR Monograph, 37, 64-65.

Farooq, U., Hussain, M., Irshad, H., Badar, N., Munir, R., \& Ali, R. (2007). Status of haemorrhagic septicemia based on epidemiology in Pakistan. Pak. Vet. J., 27(2), 67-72.

Glisson, J. R., Hofacre, C. L., \& Christensen, J. P. (2003). Fowl cholera. In Y. M. Saif, H. J. Barnes, J. R. Glisson, A. M. Fadly, L. R. McDougald, \& D. E. Swayne (Eds.), Diseases of poultry (11th ed., pp. 658-676). Iowa state press, USA.

Hutyra, F., Marek, J., \& Manninger, R. (1949). In J. R. Greig (Ed.), Special Pathology and Therapeutics of the Diseases of domestic Animals (Vol. I, p. 962). Alexander Eger Inc., Chicago, IL, U.S.A. 
Igyártó, B. Z., Erzsébet, L., Imre, O., \& Attila, M. (2006). Characterization of chicken epidermal dendritic cells. Immunology, 119(2), 278-288.

Jankovic, P. C., \& Zweig, M. (1997). Adsorption to aluminum hydroxide promotes the activity of IL-12 as an adjuvant for antibody as well as type 1 cytokine responses to HIV-1 gp120. J. Immunol, 159, 2409-17.

Kulcsár, G., Fábián, K., Barna, T., \& Virág, G. (2008). In Proc. 9th World Rabbit Congress, 2008 June, Verona, Italy, Influence of different strains and ways of inoculation on the rabbit's response to experimental infection with Pasteurella multocida (pp. 981-986).

Littledike, E. (1993). Variation of abscess formation in cattle after vaccination with a modified Pasteurella hemolytica vaccine. Am. J. Vet. Res., 54(8), 1244-1248.

Lu, Y. S., Pakes, S. P., \& Stefanu, C. (1983). Capsular and somatic serotypes of Pasteurella multocida isolates recovered from healthy and diseased rabbits in Texas. J. Clin. Microbiology, 18(2), 292-295.

Lugtenberg, B., Boxtel, R., Evenberg, D., Jong, M., Storm, P., \& Frik, J. (1986). Biochemical and immunological characterization of cell surface proteins of Pasteurella multocida strains causing atrophic rhinitis in swine. Infection and Immunity, 52(1), 175-182.

Mohamed, M. A., Mohamed, M. W. A., Ahmed, A. I., Ibrahem, A. A., \& Ahmed, M. S. (2012). Pasteurella multocida in backyard chickens in upper Egypt: Incidence with polymerase chain reaction anaylsis for capsule type, virulence in chicken embryos and microbial resistance. Veterinaria Italiana, 48(1), 77-86.

Muneer, R., Hussain, M., \& Zahoor, A. B. (2005). Efficacy of oil based haemorrhagic septicaemia vaccine: A field trial. Int. J. Agri. Biol., 4, 571-573.

Petrides, G. A., \& Bryant, E. R. (1951). An analysis of the 1949-50 fowl cholera epizootic in Texas Panhandle waterfowl. Transactions of the North American Wildlife Conference, 16, 193-216.

Rhoades, K. R., \& Rimler, R. B. (1989). Fowl cholera. In C. Adlam \& J. M. Rutter (Eds.), Pasteurella and Pasteurellosis (pp. 95-113). London, UK: Acadmic Press.

Samuel, M. D., Shadduck, D. J., Goldberg, D. R., Baranyuk, V., Sileo, L., \& Price, J. I. (1999). Antibodies against Pasteurella multocida in snow geese in the Western Arctic. J. Wildlife Dis., 35(3), 440-449.

Sarwar, N., Muhammad, K., Rabbani, M., Rana, M. Y., ..., \& Kamran, M. (2015). Factors affecting potency of hemorrhagic septicemia vaccines. Int. J. Agri. Biol., 17, 387-390.

Shah, A. H., Kamboh, A. A., Rajput, N., \& Korejo, N. A. (2008). Optimization of physico-chemical conditions for the growth of Pasteurella multocida under in vitro. J. Agri. Soc. Sci., 4, 176-179.

Shivachandra, S. B., Kumar, A. A., Gautam, R., Singh, V. P., Saxena, M. K., \& Srivastava, S. K. (2006). Identification of avian strains of Pasteurella multocida in India by conventional and PCR assays. The Vet. J., 172, 561-564.

Titche, A. (1979). Avian cholera in California. Wildlife Management Branch Administrative Report (Vol. 79-2, p. 49). California Department of Fish and Game, Sacramento, CA, U.S.A.

Tizzard, I. R. (1998). Veterinery immulogy (8th ed.). Saunders, Philadelphia, USA.

Tsuji, M., \& Matsumoto, M. (1988). Evaluation of relationship among three purified antigens from Pasteurella multocida strain P-1059 and of their protective capacities in turkeys. Am J. Vet. Res., 49(9), 1516-1521.

Wu, J. Y., Gardner, B. H., \& Kushner, N. N. (1994). Accessory cell requirements for saponin adjuvant-induced class I MHC antigen-restricted cytotoxic T-lymphocytes. Cell Immunology, 154, 393-406.

\section{Copyrights}

Copyright for this article is retained by the author(s), with first publication rights granted to the journal.

This is an open-access article distributed under the terms and conditions of the Creative Commons Attribution license (http://creativecommons.org/licenses/by/4.0/). 